ORIGINAL ARTICLE

\title{
Neonatal nosocomial sepsis in Level-III NICU: Causative pathogens and their antimicrobial sensitivity.
}

\author{
Madiha Naz', Maria Saleem², Asim Khurshid³, ${ }^{2}$ Tooba Aleem ${ }^{4}$, Muhammad Salman Zafar ${ }^{5}$
}

Article Citation: Naz M, Saleem M, Khurshid A, Aleem T, Zafar MS. Neonatal nosocomial sepsis in level-III NICU: Causative pathogens and their antimicrobial sensitivity. Professional Med J 2022; 29(3):316-322. https://doi.org/10.29309/TPMJ/2022.29.03.6295

\begin{abstract}
Objective: To find out common organism causing nosocomial sepsis in neonatal intensive care unit (NICU) and their sensitivity to frequently used antibiotics. Study Design: Cross Sectional study. Setting: NICU Pediatric Department of Nishtar Hospital Multan. Period: May 2018 to April 2019. Material \& Methods: A total of 111 neonates of either gender admitted with blood culture proven sepsis were included in the study. For culture, blood samples were taken, ensuring standard antiseptic measures, either from a peripheral vein or an artery. Any growth of bacteria after incubation of 24 to 48 hours with only BACTEC and VITEK-2 technique were included, and their drug sensitivity recorded. Demographic data along with causative microorganisms, sensitivity and resistant patterns to frequently used drugs were recorded. Results: Out of 111 patients, 61 (55\%) were male. Early onset sepsis (EOS) was present in 37 (33\%) patients and 74 (66\%) had late onset sepsis (LOS). Serratia species 33 (29.7\%) and Staphylococcus epidermidis 31 (27.9\%) were the commonest causative bacteria responsible for neonatal sepsis. Commonly involved microorganisms were highly resistant to frequently used antibiotics like ampicillin /amoxicillin, cefixime, ceftazidime. Conclusion: Nosocomial sepsis is a major health issue in NICU while and resistance of pathogens to commonly used antibiotics is alarming.
\end{abstract}

Key words: $\quad$ Antibiotics, Bacteria, Intensive Care Unit, Neonatal Infection, Neonatal Sepsis.

\section{INTRODUCTION}

Despite new advances in antibiotic therapy and improved hygienic techniques nosocomial infection is still a major component of neonatal sepsis, and is linked with significant mortality and morbidity. ${ }^{1,2}$ Neonatal sepsis is estimated to affect between 1-50/1000 live births. ${ }^{3}$ Nearly 1.6 million neonatal deaths are caused by neonatal infections worldwide. Early onset neonatal sepsis (within $1^{\text {st }}$ week of life) is generally acquired from mother during or before delivery, whereas late onset sepsis (from 8th till 28 days of life) is originated form environment either in the community or in hospital. ${ }^{4,5}$

Prenatal factors, maternal fever in last trimester, history of early rupture of membrane, flora of both the delivery place and neonatal intensive care, quality and quantity of attending physician, infection prevention protocols of the neonatal intensive care are the main determining factors for the incidence. ${ }^{4,6}$

Hand washing prior and after contact with patient and respiratory devices, aseptic measures during catheterization and removal are some of the important steps in the prevention of nosocomial infections in NICU. ${ }^{7}$ Hospital acquired sepsis is the most common infection in NICUs. ${ }^{8-10}$

Up to $30 \%$ increased chances of infection have been reported in ICU admitted patients as compared to general population. ${ }^{4}$ Nosocomial infection may be caused by a bacterial, viral or fungal organism. Among bacteria most common are staphylococci, E-coli, mycobacterium tuberculous and pseudomonas while among fungi are candida, fusarium and aspergillus. These put the patient at augmented threat of morbidity and mortality. The spectrum and sensitivity of the
1. MBBS, Postgraduate Registrar Pediatric Medicine, Nishtar University \& Hospital, Multan

2. MBBS, FCPS (Pediatric Medicine), Assistant Professor Pediatric Medicine, Nishtar University \& Hospital, Multan

3. MBBS, FCPS (Paediatric Medicine), Associate Professor Paediatric Medicine, The Children's Hospital \& ICH, Multan.

4. MBBS, Postgraduate Registrar Pediatric Medicine, Nishtar University \& Hospital, Multan

5. MBBS, Postgraduate Registrar Pediatric Medicine, Nishtar University \& Hospital, Multan

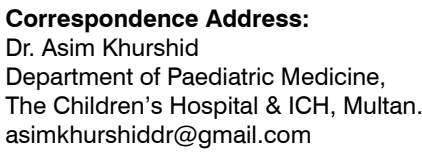

Correspondence Address:

Dr. Asim Khurshid

Department of Paediatric Medicine,

The Children's Hospital \& ICH, Multan. asimkhurshiddr@gmail.com

Article received on:

$26 / 12 / 2020$

Accepted for publication: 
pathogens responsible for sepsis can be different for each NICU and it also keeps changing over time in the same unit. Henceforth, it is important to discover the sensitivity of the responsible pathogens in order to define the empiric antibiotic regimens. ${ }^{4,11,12}$ We wanted to determine the most frequent micro-organisms responsible for the neonatal nosocomial sepsis and to determine their resistance and sensitivity pattern to regularly used antibiotics.

\section{MATERIAL \& METHODS}

This retrospective study was conducted in NICU of "Department of Pediatrics Nishtar Medical University and Hospital Multan" from May 2018 to April 2019 after approval from ethical research committee. Nosocomial sepsis was defined as presence of sepsis at least 72 hour after admission to $\mathrm{NICU}^{10}$, and neonatal sepsis was labeled as the presence of clinical signs and symptoms e.g. hypothermia, bradycardia and apnea, changes in color of skin, generalized lethargy, hypoglycemia, reluctance to feed, fever, low total leukocyte $\left(<5000 / \mathrm{mm}^{3}\right.$ count) high TLC $>25000 / \mathrm{mm}^{3}$ or low platelets $\left(<150000 / \mathrm{mm}^{3}\right)$, and confirmed by positive blood culture. One hundred and eleven neonates of either gender admitted and had sepsis proven with blood culture were enrolled. Neonates who had received antibiotics before admission or having any dysmorphism, genetic or congenital anomalies were excluded.

Place of delivery, gestational age, physical examination and outcome, were noted for each patient. For culture blood samples were taken, ensuring standard antiseptic measures, either from a peripheral vein or an artery. The results were recorded in all cases. Any growth of bacteria after incubation of 24 to 48 hours with only BACTEC and VITEK-2 technique were included, and their drug sensitivity recorded. Other relevant investigations including hematological, biochemical and radiological if performed during hospital stay were also noted.

All the data was entered and analyzed using SPSS-25. Descriptive statistics were applied to calculate mean and standard deviation for the age of the patients. Frequencies and percentage were also calculated for the categorical variables like age, gender, place of delivery, outcome, and causative organism. Sensitivity pattern of all common pathogens to frequently used drugs were recorded.

\section{RESULTS}

Out of 111 patients, 61 (55\%) were male and 50 (45\%) were female. The ages of all the neonates were in the range of $3-30$ days with $95 \% \mathrm{Cl}$ of 8.1-10.8 days for males, and 7.7-11.2 days for females. Early onset sepsis (EOS) was present in $37(33 \%)$ cases whereas late onset sepsis (LOS) was found in $74(66 \%)$ cases.

Gram-negative bacteria were more frequent than gram-positive bacteria with a frequency of $69(62.2 \%)$ and $35(31.5 \%)$ respectively, and yeast was isolated from 7 (6.3\%), among yeast 2 were Candida albicans, 3 Candida tropicalis and 1 Candida parapsilosis and 1 was candida pelliculosa. Serratia species $33(29.7 \%)$ and Staphylococcus epidermidis 31 (27.9\%) were the commonest causative bacteria responsible for neonatal sepsis. Candida species were sensitive to Fluconzalo, Variconazole and Amphotericin.

Results showed that $70(63.1 \%)$ neonates were delivered at hospital while 41 (36.9\%) were home deliveries. 68(61.3\%) were preterm while $43(38.7 \%)$ were full term neonates. Most of the neonates were expired $49(44.1 \%)$, while $34(30.6 \%)$ were discharged, 18(16.2\%) left against medical advice (LAMA), and 10(9\%) had other fate.

Figure-1, Table-III \& IV are showing sensitivity and resistance patterns of commonly used antibiotics against microorganism found in the present study. Bacteria isolated from culture were extremely resistant to frequently used antibiotics such as ampicillin /amoxicillin, cefixime, ceftazidime. Among gram -ve, serratia (29.7\%) were maximum reported specie followed by Klebsiella (14.4\%). Among gram +ve bacteria Staph epidermidis (27.9\%) was the most frequent followed by Actinobacter baumani (2.7\%). Staph epidermidis were resistant to ampicillin/ amoxicillin, Cefotaxime, Gentacin 0\%, 32 \%and 
$54 \%$ sensitivity. Gram -ve bacteria were sensitive to Chloromphenicol, Quinolone, Meronum and Tigecycline. Serratia and Klebsiella showed only $6 \%$ sensitivity to ampicillin, Cefotaxime and Meronum. Klebsiella were most sensitive to Cotrimoxazole. Gentamicin was sensitive to Serratia, Klebseilla and Pseudomonas in $24 \%$, $0 \%$ and $50 \%$ of cases respectively. Our study demonstrated $54 \%$ sensitivity of meropenam against Staphylococcus, $0 \%$ against klebsiella and $33 \%$ against Acinobacter.

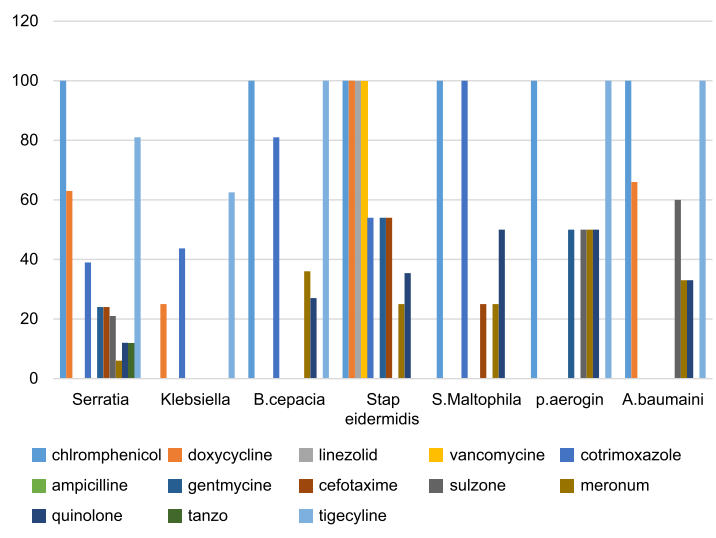

Figure-1. Sensitivity of various micro-organism to multiple antibiotics.

Serratia spp ${ }^{1}$

Klebsiella pneumoniae

Burkholderia cepacia

Staphylococcus epidermidis

S.Maltophilia

P.Aeruginosa

Acinetobacter baumannii

Candida spp

Others (enteroccous, viridans, planticola)

Total Organism

\begin{tabular}{|c|c|}
\hline $\begin{array}{l}\text { Demographic } \\
\text { Data }\end{array}$ & Frequencies (Percentages) \\
\hline Age(days) & $\begin{array}{c}\text { Male:8.1-10.8 with } 95 \% \mathrm{Cl} \\
\text { Female:7.7-11.21 with } 95 \% \mathrm{Cl}\end{array}$ \\
\hline Sex & $\begin{array}{l}\text { Male: } 61(55 \%) \\
\text { Female: } 50(45 \%)\end{array}$ \\
\hline Type of Sepsis & $\begin{array}{l}\text { EOS: } 37(33 \%) \\
\text { LOS: } 74(66 \%)\end{array}$ \\
\hline Stain & $\begin{array}{c}\text { Gram positive: } 35(31.5 \%) \\
\text { Gram negative: } 69(62.2 \%) \\
\text { Candida: } 7(6.3 \%)\end{array}$ \\
\hline Gestational age & $\begin{array}{l}\text { Preterm: } 68(61.3 \%) \\
\text { Term: } 43(38.7 \%)\end{array}$ \\
\hline Place of delivery & $\begin{array}{l}\text { Hospital: } 70(63.1 \%) \\
\text { Home: } 41(36.9 \%)\end{array}$ \\
\hline Outcome & $\begin{array}{c}\text { Expired: } 49(44.1 \%) \\
\text { Discharged: } 34(30.6 \%) \\
\text { LAMA: } 18(16.2 \%) \\
\text { Shifted: } 10(9 \%)\end{array}$ \\
\hline \multicolumn{2}{|c|}{$\begin{array}{l}\text { Table-I. Demographic data of neonate with } \\
\text { nosocomial sepsis }(n=111) \text {. }\end{array}$} \\
\hline Percentag & Cumulative Percent \\
\hline $29.7 \%$ & 72.1 \\
\hline $14.4 \%$ & 33.3 \\
\hline $9.9 \%$ & 12.6 \\
\hline $27.9 \%$ & 100 \\
\hline $3.6 \%$ & 36.9 \\
\hline $1.8 \%$ & 42.3 \\
\hline $2.7 \%$ & 2.7 \\
\hline $6.3 \%$ & 18.9 \\
\hline $3.6 \%$ & 40.5 \\
\hline $100 \%$ & \\
\hline
\end{tabular}

Table-II. Various bacteria found to be responsible for nosocomial sepsis.

\begin{tabular}{|c|c|c|c|c|c|c|c|c|}
\hline \multirow{2}{*}{ Antibiotics } & \multicolumn{2}{|c|}{ Serratia Specie } & \multicolumn{2}{|c|}{ Klebsiella Pneumoniae } & \multicolumn{2}{|c|}{ Burkholaria Cepacia } & \multicolumn{2}{|c|}{ Staphylococcus Epidermidis } \\
\hline & $\mathbf{S} / \mathbf{R}$ & Sensitivity & S/R & Sensitivity & S/R & Sensitivity & $\mathbf{S} / \mathbf{R}$ & Sensitivity \\
\hline Doxycycline & $21 / 12$ & $63 \%$ & $4 / 12$ & $25 \%$ & - & - & $31 / 0$ & $100 \%$ \\
\hline Vancomycine & - & - & - & - & - & - & $31 / 0$ & $100 \%$ \\
\hline Cotrimoxazole & $13 / 20$ & $39 \%$ & $7 / 9$ & $43.7 \%$ & $9 / 2$ & $81 \%$ & $17 / 14$ & $54 \%$ \\
\hline Ampicillin/Amoxillicn & $0 / 33$ & $0 \%$ & $0 / 16$ & $0 \%$ & $0 / 11$ & $0 \%$ & $0 / 31$ & $0 \%$ \\
\hline Sulzone & $7 / 26$ & $21 \%$ & $0 / 16$ & $0 \%$ & $0 / 11$ & $0 \%$ & $0 / 31$ & $0 \%$ \\
\hline Meronem & $2 / 31$ & $6.0 \%$ & $0 / 16$ & $0 \%$ & $4 / 7$ & $36 \%$ & $8 / 23$ & $25 \%$ \\
\hline Quinolones & $4 / 29$ & $12 \%$ & $0 / 16$ & $0 \%$ & $3 / 8$ & $27 \%$ & $12 / 19$ & $35.4 \%$ \\
\hline Tanzo & $4 / 29$ & $12 \%$ & $0 / 16$ & $0 \%$ & - & - & - & - \\
\hline Tigecyline & $27 / 6$ & $81 \%$ & $10 / 6$ & $62.5 \%$ & $11 / 0$ & $100 \%$ & - & - \\
\hline
\end{tabular}

Table-III. Sensitivity of various bacteria responsible for neonatal sepsis to commonly used antibiotics.

$\mathrm{S}=$ Sensitive, $\mathbf{R}=$ Resistant, - Indicating not checked 


\begin{tabular}{|c|c|c|c|c|c|c|}
\hline \multirow{2}{*}{ Antibiotics } & \multicolumn{2}{|c|}{ S. Maltophila } & \multicolumn{2}{|c|}{ P. Aeroginosa } & \multicolumn{2}{|c|}{ Acinetobacter Baumannii } \\
\hline & S/R & Sensitivity & S/R & Sensitivity & $\mathbf{S} / \mathbf{R}$ & Sensitivity \\
\hline Chloramphenicol & $4 / 0$ & $100 \%$ & $2 / 0$ & $100 \%$ & $3 / 0$ & $100 \%$ \\
\hline Linezolid & - & - & - & & - & - \\
\hline Vancomycine & - & - & - & - & - & \\
\hline Ampicillin/Amoxil & $0 / 4$ & $0 \%$ & $0 / 2$ & $0 \%$ & $0 / 3$ & $0 \%$ \\
\hline Gentacin & - & - & $1 / 1$ & $50 \%$ & $0 / 3$ & $0 \%$ \\
\hline Cefotaxime & $1 / 3$ & $25 \%$ & $0 / 2$ & $0 \%$ & $0 / 3$ & $0 \%$ \\
\hline Sulzone & $0 / 4$ & $0 \%$ & $1 / 1$ & $50 \%$ & $2 / 1$ & $60 \%$ \\
\hline Tigecyline & - & - & $2 / 0$ & $100 \%$ & $3 / 0$ & $100 \%$ \\
\hline
\end{tabular}

Table-IV. Sensitivity of various bacteria responsible for neonatal sepsis to commonly used antibiotics. $\mathbf{S}=$ Sensitive, $\mathbf{R}=$ Resistant, - Indicating not checked

\section{DISCUSSION}

Nosocomial sepsis is a main burden in NICU and is difficult to control because of resistance pattern of responsible pathogens. ${ }^{13-15}$ We noted that male babies were $55 \%$, which is close to the findings of Muhammad et al and Shaw et al. ${ }^{16,17}$ This could be due to fact that female sex hormones show shielding effects in septic conditions while male hormones suppress immunity as reported in Angele et al. ${ }^{18} \mathrm{EOS}$ was present in $33 \%$ cases while LOS $66 \%$ which correlated well with Muhammad et al and Thakur et al. ${ }^{16,19}$ Gram-negative bacteria were more frequent than gram-positive bacteria with a frequency of $69(62.2 \%)$ and 35 (31.5\%) respectively, and yeast was isolated from 7 (6.3\%). These results are consistent with international and local studies conducted by Muhammad et al, Yalez et al, Paven Kumar and Awoniyi et al. ${ }^{16,20,21,22}$ Some studies reported gram positive as most frequent organism like Abdelatif et al. ${ }^{23}$ The low incidence of gram positive sepsis in our study can be credited to low infection rates with Group B Streptococcus infection in Asia. ${ }^{24}$ Difference in bacterial flora from place to place and time to time might also be a contributing factor. ${ }^{20,25,26}$

Bacteria isolated from culture were extremely resistant to frequently used antibiotics such as ampicillin/amoxicillin, cefixime, ceftazidime.
Antibiotic resistance is a problem faced worldwide. ${ }^{27}$ In the our study, a huge number of Gram positive and Gram negative pathogens showed inconstant pattern of sensitivity to commonly used antibiotics. Many recent studies also show similar results. ${ }^{16,26}$ Among gram ve, serratia were maximum recorded specie followed by Klebsiella, while Shrestha et al and others reported Klebsiella as most common organism. ${ }^{27,28}$

Among gram +ve bacteria Staph epidermidis is most frequent followed by Actinobacter baumani, a study done in Nepal also reported high prevalence of Actinobacter ${ }^{3}$ while high prevalence of Staph epidermidis as nosocomial pathogen could be because of excessive skin breach and insertion of central catheters as reported in ${ }^{29}$ Gram + ve bacteria were sensitive to Linezolid, Vancomycine and Chloramphenicol.

Staph epidermidis were resistant to ampicillin/ amoxicillin, Cefotaxime, Gentacin 0\%, 32 \%and $54 \%$ sensitivity recorded in our study while Shrestha et al reported $58.5 \%$ and $31.5 \%$ resistance ${ }^{28}$ to ampicillin and gentamycin respectively. High resistance was also noted in Movahiden et al and many other. ${ }^{26,29}$ 
In our study, gram -ve bacteria were sensitive to Chloromphenicol, Quinolone, Meronem and Tigecycline. Serratia and Klebsiella showed only $6 \%$ sensitivity to ampicillin, Cefotaxime and Meronum. Aurangzeb et al reported very high resistance against these antibiotics. ${ }^{30}$ However, they showed good susceptibility to Tigecycline $81 \%$ and $62.5 \%$ recorded in our study similar to Pokhrel et al. ${ }^{27}$

Klebsiella were most sensitive to Cotrimoxazole. Although, studies in the past have shown favorable sensitivity patternof3rd generationcephalosporins but our study revealed higher resistance of gram negative isolates to 3rd generation cephalosporins. Aurangzeb et all reported $11 \%$ sensitivity of gram -ve to Cephalosporins. Now a days, third generation Cephalosporin resistance is increasing rapidly and has been widely reported by recent studies. ${ }^{9,26,29}$ Aminoglycosides have shown inconstant resistance pattern against different pathogens. Gentamicin was sensitive to Serratia, Klebseilla and Pseudomonas in $24 \%, 0 \%$ and $50 \%$ of cases respectively. While Sherstha et al reported $77 \%$ resistance to genatmycin against Klebseilla nearly the same results. Our study demonstrated $54 \%$ sensitivity of meropenam against Staphylococcus, 0\% against klebsiella and 33\% against Acinobacter while Muhammad et all reported $100 \%$ sensitivity against Acinetobacter and Enterobacter. ${ }^{16}$ Shaw et $\mathrm{al}^{17}$ has described $100 \%$ sensitivity of Meronum against Staphylococcus in addition to Acinetobacter, Klebseila, and Enterobacter.

High resistance of gram negative pathogens to piperacillin- tazobactam has been reported recently by Shrestha et al (87.5\%) and many others while our study reported $100 \%$ resistance. ${ }^{28}$ While another study reported higher sensitivity to piperacillin- tazobactam as compared to our result. $^{31}$

As this was a single hospital study, our revelations cannot be generalized. Sample size was comparatively small as well. Blood culture must be sent on regular basis and sensitivity of bacteria checked time to time to keep check on the change of the flora and sensitivity to commonly antibiotics.
Sterilization techniques should be improved, skin puncture should be minimum and catheters should be removed early. Frequent hand washing is important to control nosocomial sepsis. Each hospital should have its own empirical regimen to avoid misuse of antibiotics.

\section{CONCLUSION}

Serratia were the commonest gram-negative and Staph. Epidermidis as the commonest grampositive bacteria causing nosocomial sepsis the commonly used antibiotics such as ampicillin, Cefotaxime, and gentacin are ineffective. Less commonly used drugs like Tigecycine, Tanzo, Cotrimoxazole, Chlromphenicol, and Doxycycline are relatively more sensitive than commonly used antibiotics. Resistance to commonly used antibiotics is mainly because of unwise choice of antibiotic regimens, improper hygiene measures. New drugs are slow to develop and if we did not control these practices no drug will be left to treat simple infections in future.

\section{Copyright $\subseteq 27$ Feb, 2021.}

\section{REFERENCES}

1. Baqui AH, Saha SK, Ahmed AS, Shahidullah M, Quasem I, Roth DE, et al. Safety and efficacy of alternative antibiotic regimens compared with 7 day injectable procaine benzylpenicillin and gentamicin for outpatient treatment of neonates and young infants with clinical signs of severe infection when referral is not possible: A randomised, open-label, equivalence trial. Lancet Glob Health. 2015; 3(5):e279-87.

2. Gilfillan M, Bhandari V. Biomarkers for the diagnosis of neonatal sepsis and necrotizing enterocolitis: Clinical practice guidelines. Early Hum. Dev. 2017; 105:25-33.

3. Ershad M, Mostafa A, Dela Cruz M, Vearrier D. Neonatal sepsis. Curr Emerg Hosp Med Rep. 2019; 7(3):83-90.

4. Zaidi AKM, Thaver D, Ali SA, Khan TA. Pathogens associated with sepsis in newborns and young infants in developing countries. Pediatr Infect Dis J. 2009; 28(1 Suppl):S10-8.

5. Ansari S, Nepal HP, Gautam R, Shrestha S, Neopane P, Chapagain ML. Neonatal septicemia in Nepal: Earlyonset versus late-onset. Int J Pediatr. 2015; 2015:1-6. 
6. Roy M, Bhatt M, Maurya V, Arya S, Gaind R, Chellani H. Changing trend in bacterial etiology and antibiotic resistance in sepsis of intramural neonates at a tertiary care hospital. J Postgrad Med. 2017; 63(3):162.

7. Timsit JF, Baleine J, Bernard L, Calvino-Gunther S, Darmon M, Dellamonica J, et al. Expert consensusbased clinical practice guidelines management of intravascular catheters in the intensive care unit. Ann Intensive Care. 2020; 10(1):118.

8. Prabhu K, Bhat S, Rao S. Bacteriologic profile and antibiogram of blood culture isolates in a pediatric care unit. J Lab Physicians. 2010; 2(2):85-8.

9. Sarangi K, Pattnaik D, Mishra S, Nayak M, Jena J. Bacteriological profile and antibiogram of blood culture isolates done by automated culture and sensitivity method in a neonatal intensive care unit in a tertiary care hospital in Odisha, India. Int J Adv Med. 2015; 387-92.

10. Gupta S, Singh VK, Singhal S, Chowdhary P. Neonatal sepsis in a tertiary care hospital in Delhi, India: study of microbial profile and antimicrobial susceptibility pattern. Int J Contemp Pediatr. 2019; 6(2):384.

11. Chauhan R, Gupta S, Dalal JS, Jhajra S, Gathwala G. Antimicrobial profile and antibiotic susceptibility of neonatal sepsis in neonatal intensive care unit of tertiary care hospital of North India. Ind Jour of Publ Health Res Dev. 2019; 10(8):733.

12. Jajoo M, Manchanda V, Chaurasia S, Sankar MJ, Gautam $\mathrm{H}$, Agarwal $\mathrm{R}$, et al. Alarming rates of antimicrobial resistance and fungal sepsis in out born neonates in North India. PLoS One. 2018; 13(6):e0180705.

13. Craft A, Finer N. Nosocomial coagulase negative staphylococcal (CoNS) catheter-related sepsis in preterm infants: Definition, diagnosis, prophylaxis, and prevention. J Perinatol. 2001; $21(3): 186-92$.

14. Clark R, Powers R, White R, Bloom B, Sanchez $\mathrm{P}$, Benjamin DK Jr. Prevention and treatment of nosocomial sepsis in the NICU. J Perinatol. 2004; 24(7):446-53.

15. Zea-Vera A, Ochoa TJ. Challenges in the diagnosis and management of neonatal sepsis. J Trop Pediatr. 2015; 61(1):1-13.

16. Muhammad Z, Ahmed A, Hayat U, Wazir MS, Ullah $R$, Waqas $H$. Neonatal sepsis: Causative bacteria and their resistance to antibiotics. J Ayub Med Coll Abbottabad. 2010; 22(4):33-6.
17. Shaw CK, Shaw P, Thapalial A. Neonatal sepsis bacterial isolates and antibiotic susceptibility patterns at a NICU in a tertiary care hospital in western Nepal: A retrospective analysis. Kathmandu Univ Med J. 2007; 5(2):153-60.

18. Angele MK, Pratschke S, Hubbard WJ, Chaudry IH. Gender differences in sepsis. Virulence. 2014; 5(1):12-9.

19. Thakur S, Thakur K, Sood A, Chaudhary S. Bacteriological profile and antibiotic sensitivity pattern of neonatal septicaemia in a rural tertiary care hospital in North India. Indian J Med Microbiol. 2016; 34(1):67.

20. Yalaz M, Cetin H, Akisu M, Aydemir S, Tunger A, Kültürsay N. Neonatal nosocomial sepsis in a levelIII NICU: Evaluation of the causative agents and antimicrobial susceptibilities. Turk J Pediatr. 2006; 48(1):13-8.

21. Pavan KD, Mohan J, Rakesh P, Prasad J, Joseph L. Bacteriological profile of neonatal sepsis in a secondary care hospital in rural Tamil Nadu, Southern India. J Family Med Prim Care. 2017; 6(4):735.

22. Awoniyi DO, Udo SJ Oguntibeju OO. An epidemiological survey of neonatal sepsis in a hospital in Western Nigeria. African J Microbiol Res. 2009; 3(6):385-9.

23. Abdellatif M, Al-Khabori M, Rahman AU, Khan AA, AlFarsi A, Ali K. Outcome of late-onset neonatal sepsis at a tertiary hospital in Oman. Oman Med J. 2019; 34(4):302-7.

24. Dalal P, Gathwala G, Gupta M, Singh J. Bacteriological profile and antimicrobial sensitivity pattern in neonatal sepsis: A study from North India. Int $\mathrm{J}$ Res Med Sci. 2017; 5(4):1541-5.

25. Sundaram V, Kumar P, Dutta S, Mukhopadhyay K, Ray $P$, Gautam V, et al. Blood culture confirmed bacterial sepsis in neonates in a North Indian tertiary care center: changes over the last decade. Jpn $\mathrm{J}$ Infect Dis. 2009; 62(1):46-50.

26. Movahedian AH, Moniri R, Mosayebi Z. Bacterial culture of neonatal sepsis. Iran J Public Health. 2006; 35(4):84-9.

27. Pokhrel B, Koirala T, Shah G, Joshi S, Baral P. Bacteriological profile and antibiotic susceptibility of neonatal sepsis in neonatal intensive care unit of a tertiary hospital in Nepal. BMC Pediatr. 2018; 18(1):208. 
28. Shrestha S, Shrestha NC, Dongol Singh S, Shrestha RPB, Kayestha S, Shrestha M, et al. Bacterial isolates and its antibiotic susceptibility pattern in NICU. Kathmandu Univ Med J. 2013; 11(41):66-70.

29. Peixoto PB, Massinhani FH, Santos KR, Chamon RC, Silva RB, Correa FE, et al. Methicillin-resistant Staphylococcus epidermidis isolates with reduced vancomycin susceptibility from bloodstream infections in a neonatal intensive care unit. $\mathrm{J}$ Med Microbiol. 2020; 69(1):41-5.
30. Aurangzeb B, Hameed A. Neonatal sepsis in hospitalborn babies: Bacterial isolates and antibiotic susceptibility patterns. J Coll Physicians Surg Pak. 2003; 13(11):629-32.

31. Dalal P, Gathwala G, Gupta M, Singh J. Bacteriological profile and antimicrobial sensitivity pattern in neonatal sepsis: A study from North India. Int J Res Med Sci. 2017; 5(4):1541-5.

\begin{tabular}{|c|c|c|c|}
\hline \multicolumn{4}{|c|}{ AUTHORSHIP AND CONTRIBUTION DECLARATION } \\
\hline No. & Author(s) Full Name & Contribution to the paper & Author(s) Signature \\
\hline 1 & Madiha Naz & $\begin{array}{l}\text { Data collection, Data } \\
\text { analysis. }\end{array}$ & 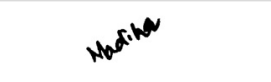 \\
\hline 2 & Maria Saleem & $\begin{array}{l}\text { Methodology, Literature } \\
\text { review. }\end{array}$ & $\mathbb{A}$ \\
\hline 3 & Asim Khurshid & $\begin{array}{l}\text { Study Concept, Drafting, } \\
\text { Proof Reading. }\end{array}$ & 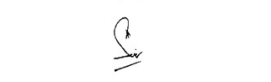 \\
\hline 4 & Tooba Aleem & Data Collection. & Fous \\
\hline 5 & Muhammad Salman Zafar & $\begin{array}{l}\text { Literature Review, Data } \\
\text { interpretation. }\end{array}$ & M. Salumelly \\
\hline
\end{tabular}

